\title{
Measurement of the components of nonexercise activity thermogenesis.
}

Citation for published version (APA):

Levine, J., Melanson, E. L., Westerterp, K. R., \& Hill, J. O. (2001). Measurement of the components of nonexercise activity thermogenesis. American Journal of Physiology : Endocrinology and Metabolism, 281, E670-E675. https://doi.org/10.1152/ajpendo.2001.281.4.E670

Document status and date:

Published: 01/01/2001

DOI:

10.1152/ajpendo.2001.281.4.E670

Document Version:

Publisher's PDF, also known as Version of record

\section{Document license:}

Taverne

\section{Please check the document version of this publication:}

- A submitted manuscript is the version of the article upon submission and before peer-review. There can be important differences between the submitted version and the official published version of record.

People interested in the research are advised to contact the author for the final version of the publication, or visit the DOI to the publisher's website.

- The final author version and the galley proof are versions of the publication after peer review.

- The final published version features the final layout of the paper including the volume, issue and page numbers.

Link to publication

\footnotetext{
General rights rights.

- You may freely distribute the URL identifying the publication in the public portal. please follow below link for the End User Agreement:

www.umlib.nl/taverne-license

Take down policy

If you believe that this document breaches copyright please contact us at:

repository@maastrichtuniversity.nl

providing details and we will investigate your claim.
}

Copyright and moral rights for the publications made accessible in the public portal are retained by the authors and/or other copyright owners and it is a condition of accessing publications that users recognise and abide by the legal requirements associated with these

- Users may download and print one copy of any publication from the public portal for the purpose of private study or research.

- You may not further distribute the material or use it for any profit-making activity or commercial gain

If the publication is distributed under the terms of Article $25 \mathrm{fa}$ of the Dutch Copyright Act, indicated by the "Taverne" license above, 


\title{
Measurement of the components of nonexercise activity thermogenesis
}

\author{
JAMES LEVINE, ${ }^{1}$ EDWARD L. MELANSON,${ }^{2}$ KLAAS R. WESTERTERP ${ }^{3}$ AND JAMES O. HILL ${ }^{2}$ \\ ${ }^{1}$ Endocrine Research Unit, Mayo Clinic, Rochester, Minnesota 55905; ${ }^{2}$ Center for Human Nutrition, \\ University of Colorado Health Sciences Center, Denver, Colorado 80220; and ${ }^{3}$ Department of \\ Human Biology, University of Maastricht, 6200 MD Maastricht, The Netherlands
}

Received 27 November 2000; accepted in final form 3 May 2001

Levine, James, Edward L. Melanson, Klaas R. Westerterp, and James O. Hill. Measurement of the components of nonexercise activity thermogenesis. Am J Physiol Endocrinol Metab 281: E670-E675, 2001.-Nonexercise activity thermogenesis (NEAT) accounts for the vast majority of nonresting metabolic rate and changes in NEAT-predicted susceptibility to fat gain with overfeeding. Measuring physical activity and its components in free-living humans has been a long-standing challenge. In this study, we combine information about lightweight sensors that capture data on body position and motion with laboratory measures of energy expenditure to calculate nonfidgeting NEAT. This measurement of nonfidgeting NEAT was compared with total NEAT measured in a room calorimeter in 11 healthy subjects. The measurement of nonfidgeting NEAT accounted for $85 \pm 9 \%$ of total NEAT measured in the room calorimeter. The intraclass correlation coefficient for the two methods was 0.86 (95\% confidence interval $0.56,0.96 ; P<0.05$ ). This suggests that $86 \%$ of the variance is attributable to between-subject variance and $14 \%$ to between-method disagreement. These instruments are applicable to free-living subjects; they are stand-alone, are lightweight, and allow normal daily activities. This novel technology has potential application for not only assessing NEAT but also tracking physical activity in free-living humans.

energy expenditure; body movement; obesity

INCREASES in nonexercise activity thermogenesis (NEAT) predicted resistance to fat gain with experimental overfeeding (13). However, measuring NEAT, particularly in free-living subjects, is a technical challenge, because NEAT comprises several components, namely, walking, sitting, standing, transition of body position (e.g., sitting to standing), and other movements that might be termed "fidgeting." Nonetheless, we believe that it is mandatory to understand the components of NEAT and how these components are modulated with changing energy balance. This information will provide insight into the mechanism by which NEAT influences changes in energy expenditure (EE) and how best to target therapies that aim to change NEAT in patients with disorders such as obesity.

Address for reprint requests and other correspondence: J. A. Levine, Endocrine Research Unit, 5-194 Joseph, Mayo Clinic, 200 First St., SW, Rochester, MN 55905 (E-mail: levine.james@mayo.edu).
Our approach to studying NEAT is to divide it into three components. The first component is the $\mathrm{EE}$ of body posture, namely, the energy expended while sitting and standing and resulting from transitions in body posture. The second component is the EE of ambulation. The third component is the quantity of other movements, namely, fidgeting. Categorization of NEAT into these components allowed us to generate a testable hypothesis.

Our hypothesis was that nonfidgeting NEAT represents the majority of NEAT and can be predicted by combining measurements of 1) body position derived from inclinometers (tilt sensors), 2) body motion quantified using a validated accelerometer system, and 3) laboratory measurements of the $\mathrm{EE}$ of sitting and standing, transitions of body posture, and walking.

A secondary hypothesis that we tested was that the body motion that occurs while lying, sitting, and standing (i.e., a determination of fidgeting) can be quantified using an accelerometer system.

We conducted a study to compare NEAT predicted by the above approach with NEAT measured using a whole-room calorimeter. We used sensors to capture data on body position and motion and combined this information with laboratory measures of EE to predict nonfidgeting NEAT. We compared this predicted value for NEAT with NEAT measured using a room calorimeter. Also, accelerometer outputs for body motion while subjects were lying, sitting, and standing were summed to ascertain whether this value represented "fidgeting-like movement."

\section{SUBJECTS AND METHODS}

\section{Subjects}

Eleven healthy, nonobese volunteers ( 5 males, 6 females, $34 \pm 5 \mathrm{yr}, 66 \pm 9 \mathrm{~kg}$, body mass index $23 \pm 3 \mathrm{~kg} / \mathrm{m}^{2}$ ) were recruited. Subjects had no chronic illnesses, were not on medications, and reported no fluctuation in body weight $>2$ $\mathrm{kg}$ for the 3 mo before the study.

\footnotetext{
The costs of publication of this article were defrayed in part by the payment of page charges. The article must therefore be hereby marked "advertisement" in accordance with 18 U.S.C. Section 1734 solely to indicate this fact.
} 


\section{Indirect Calorimeters}

Metabolic cart. The metabolic cart was a SensorMedics 229N (Yorba Linda, CA) flow-over, indirect calorimeter (12). The calorimeter was calibrated for flow daily using a 3-liter calibrated syringe and before each measurement with two primary standard span gases $\left(4 \% \mathrm{CO}_{2}-16 \% \mathrm{O}_{2}-26 \% \mathrm{O}_{2}\right.$; balance $\mathrm{N}_{2}$ ). Gas flow through the system was modulated to maintain $\mathrm{O}_{2}$ and $\mathrm{CO}_{2}$ concentrations within normal physiological range. Data were integrated every $30 \mathrm{~s}$ and stored on a PC. The system was tested by burning a measured mass high-purity ethanol (AAPER Alcohol and Chemical, Shelbyville, $\mathrm{KN}$ ) within the system by use of a specialized apparatus (SensorMedics). Expired air was collected using a fullface transparent mask (Scott Aviation, Lancaster, NY). The face mask was connected to the calorimeter by $6 \mathrm{~m}$ of $22-\mathrm{mm}$ diameter leak-proof tubing (Hans Rudolph, Kansas, MO). This system permits almost complete mobility with minimal agitation. The response time for the system is $\sim 20 \mathrm{~s}$.

Room calorimeter. Total EE was measured in the wholeroom calorimeter at the Center for Human Nutrition, University of Colorado Health Sciences Center (UCHSC) (17). The subject's $\mathrm{O}_{2}$ consumption and $\mathrm{CO}_{2}$ production were determined from the measured flow rate and the differences in $\mathrm{O}_{2}$ and $\mathrm{CO}_{2}$ concentrations between entering and exiting air. Values were corrected for temperature, barometric pressure, and humidity. Total EE was calculated using published equations (11). Values for all measured variables were collected each minute and stored on a PC.

\section{Inclinometer System}

The inclinometer was a stand-alone system and employed two tilt sensors (Crossbow CXTA02, San Jose, CA) connected to analog ports of a data logger (AD128CX, Valitec, Dayton, $\mathrm{OH})$. The inclinometers were secured to the lateral aspect of the trunk and to the lateral aspect of the mid-thigh by means of clear polycarbonate plastic holders and tape, which ensured that the sensors remained correctly oriented on the trunk and thigh, respectively (Fig. 1). The inclinometer/data logger unit weighed $343 \mathrm{~g}$ and was powered by a $9 \mathrm{~V}$ battery (Ultralife, Newark, NJ). At the end each experiment, voltage outputs from the inclinometers/data logger were downloaded, via a serial connection, to a PC. The voltage data streams were first interrogated to ascertain whether the respective sensor was closest to the vertical or horizontal plane. "Vertical" was equivalent to voltages that ranged from 0.83 to $3.6 \mathrm{~V}$ (mean \pm SD $2.7 \pm 0.3 \mathrm{~V}$ ) and "horizontal" from 2.7 to $5.0 \mathrm{~V}$ $(4.4 \pm 0.1 \mathrm{~V})$. The information from the two sensors was then combined and determinations were made of "lying," "sitting," and "standing". Lying was designated when both sensor voltages indicated horizontal. Sitting was designated when the thigh sensor indicated horizontal and the trunk sensor vertical. Standing was designated when both sensor voltages indicated vertical. When the sensors indicated a change in posture (e.g., sitting to standing, sitting to lying, etc.) this represented a "transition." Data streams were analyzed using macros written in Excel 2000 (Microsoft, Seattle, WA).

\section{Tracmor Accelerometer}

The triaxial accelerometer (4-6) comprised three uniaxial piezoresistive accelerometers (ICSensors 3031-010, Druck, The Netherlands) mounted orthogonally in a resin block $(50 \times 30 \times 8 \mathrm{~mm}, 16 \mathrm{~g})$, whereby each axis is independently sensed. The accelerometer was worn on the lower back, attached using a $70 \times 85-\mathrm{mm}$ piece of adhesive plastic (Tegaderm, 3M, Minneapolis, MN) (Fig. 1). A cable connected

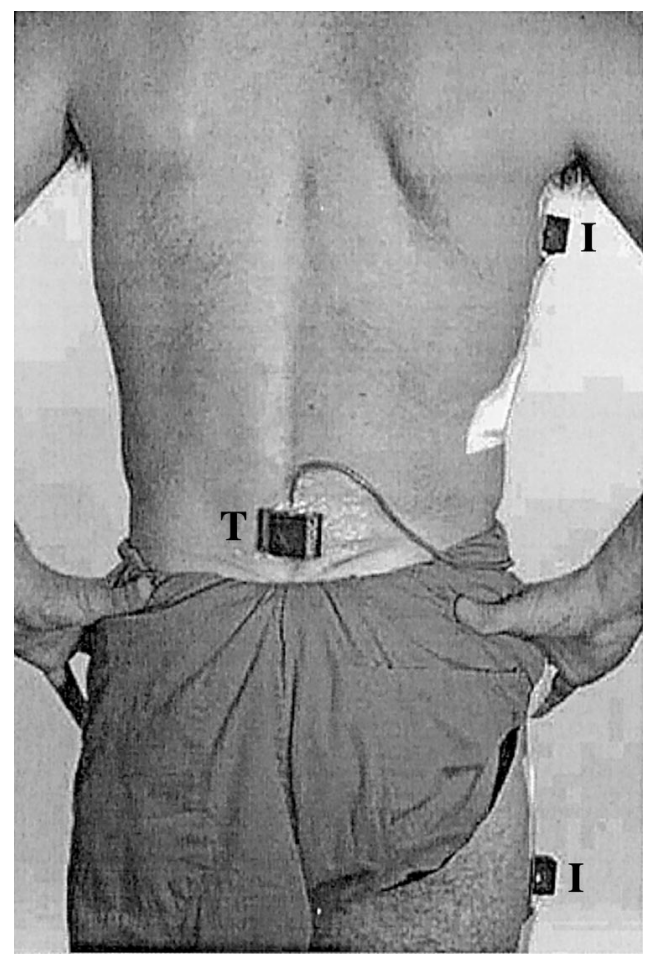

Fig. 1. Position of sensors. I, inclinometer; T, Tracmor accelerometer.

the accelerometer to a portable data logger (Tattletale $5 \mathrm{~F}$, Onset Computer, $512 \mathrm{kB}, 16$ bit, $10 \times 70 \times 35 \mathrm{~mm}, 250 \mathrm{~g})$. Data for each axis were amplified and filtered $(0.11 \mathrm{~Hz}$ high pass, $20 \mathrm{~Hz}$ low pass) to attenuate the $\mathrm{DC}$ responses, and the sums of the rectified and integrated acceleration curves for the three axes were measured. Data were recorded continuously and downloaded, via a serial connection, to a PC.

\section{Experimental Protocol}

Overnight fasted, rested subjects were admitted into a standard room in the General Clinical Research Center at UCHSC, Denver, Colorado at 0700. Inclinometers were attached to the lateral aspects of the torso and thigh, and the Tracmor unit no. 7 was attached to the back. By use of the metabolic cart, the basal metabolic rate (BMR) was measured for $30 \mathrm{~min}$. Sitting and standing EE values were then each measured for 20 min while subjects were motionless. Transition EE was measured next; here, subjects moved from seated to standing position every $6 \mathrm{~s}$ for $15 \mathrm{~min}$, which was standardized using a tape recording (Fig. 2).

Subjects then entered the room calorimeter for measurement of Total EE for the next $250 \mathrm{~min}$. After $60 \mathrm{~min}$ of rest, resting $\mathrm{EE}$ was measured for $30 \mathrm{~min}$. The next $190 \mathrm{~min}$ represented the "activity period" of the protocol (Fig. 2). For 144 min, subjects were instructed to change posture (either sitting, standing or lying) every 6 min using a standardized order. Subjects were encouraged to perform varied, spontaneous physical activities while maintaining the instructed posture; while standing, subjects were allowed to ambulate (if desired). Subjects were then instructed to walk for $20 \mathrm{~min}$ on a treadmill at a self-selected pace compatible with ambling at home or work $(\sim 1 \mathrm{mph})$. For the final $20 \mathrm{~min}$, subjects were instructed to walk at a self-selected pace compatible with purposeful locomotion (e.g., walking to an ap- 

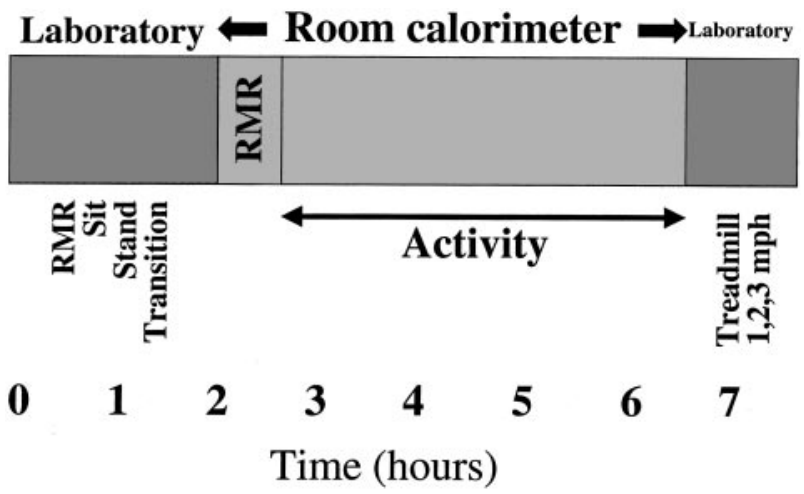

Fig. 2. Summary of room calorimeter protocol. RMR, resting metabolic rate.

pointment, $\sim 2.5 \mathrm{mph}$ ). Also, there were two optional, 10-min, bathroom use opportunities.

After completion of the room calorimeter segment, subjects were released from the chamber and rested for $30 \mathrm{~min}$. By use of the metabolic cart, EE was then measured with the subject standing motionless ( $0 \mathrm{mph}$ ) and then walking at 1,2 , and $3 \mathrm{mph}$ on a treadmill. This part of the protocol was performed after the room calorimeter measurements, because we did not want the EE of walking to impact on the low-activity EE measurements conducted during the room calorimeter protocol. After the treadmill walking, the instruments were removed from the subject, and the data were downloaded onto a PC. All measurements were made at $22^{\circ} \mathrm{C}$.

\section{Data Analysis}

The term NEAT Instruments refers to the prediction of nonfidget-NEAT made using the accelerometer/inclinometer/ metabolic cart approach, and the term NEAT Room calorimeter refers to NEAT measured in the room calorimeter.

$N E A T^{\text {Instruments }}$. For the activity period (Fig. 2), inclinometer outputs were used to identify the number of minutes a subject spent lying, sitting, and being upright (standing plus ambulating). For the time spent upright, Tracmor output distinguished standing (Tracmor no. 7 output $\leq 1,900$ TU) from walking $(>1,900 \mathrm{TU})(5)$. For the activity period, we could thereby calculate the time spent standing, the time spent walking, mean Tracmor output for walking, and mean Tracmor output for nonwalking activities (lying, sitting, and standing). For the activity period, inclinometer data were used to determine the number of transitions made between postures (e.g., sitting to standing).

Metabolic cart measurements were used to calculate BMR and the EE of sitting, standing, transitions, and walking at 0 , 1, 2, and $3 \mathrm{mph}$. For the activity period (Fig. 2), the EE for sitting, standing, and transitions (EE sitting, EE standing, and EE transitions, respectively) was calculated by multiplying the time engaged in each activity (or number of transitions) by the EE for that activity. To calculate walking EE for the activity period, a regression equation was derived from the metabolic cart treadmill experiment to relate Tracmor output to EE. Walking EE for the activity period (EE walking) was calculated using this regression equation and the mean Tracmor output for walking during the activity period.

NEAT ${ }^{\text {Instruments }}$ for the activity period (Fig. 2) was calculated from: $\mathrm{NEAT}^{\text {Instruments }}=\mathrm{EE}$ sitting + EE standing + EE transitions + EE walking.

It is important to note that NEAT ${ }^{\text {Instruments }}$ does not include the EE of fidgeting, which might be defined as the component of NEAT that is not accounted for by NEAT Instruments.

NEAT Room calorimeter. During the study, subjects remained fasted, and thus there was zero thermic effect of food (TEF). NEAT Room calorimeter for the activity period (Fig. 2) was calculated from: $\mathrm{NEAT}^{\text {Room calorimeter }}=$ total $\mathrm{EE}^{\text {Room calorimeter }}-$ resting EE Room calorimeter.

To address our primary hypothesis, that NEAT Instruments compared favorably with NEAT ${ }^{\text {Room calorimeter }}$, direct numerical comparison was made and the intraclass correlation coefficient was calculated (corrected for the fixed bias that exists between the two methods). To address our secondary hypothesis, that nonwalking Tracmor output might reflect part of the unaccounted-for total EE (i.e., fidgeting-like activity), total EE predicted using the instruments was subtracted from total EE measured using the room calorimeter, and the difference was compared with nonwalking Tracmor output by means of linear regression analysis. Data are expressed as means \pm SD.

\section{RESULTS}

For the metabolic cart, repeated alcohol burn experiments yielded $\mathrm{CO}_{2}$ and $\mathrm{O}_{2}$ recoveries $\sim 98 \%$. The $\mathrm{SD}$ of the respiratory quotient for the last $15 \mathrm{~min}$ of these measurements was $<1 \%$ of the mean. For 24 subjects, $38 \pm 11 \mathrm{yr}, 76 \pm 21 \mathrm{~kg}$, test-retest differences for duplicate measurements of resting EE and sitting and standing EE were $<3 \%$. For the room calorimeter, butane burn experiments showed recoveries of $>96 \%$.

For the 190-min activity period (Table 1), subjects spent on average $23 \pm 5 \%$ of the time lying, $23 \pm 4 \%$ sitting, $21 \pm 4 \%$ standing, and $33 \pm 6 \%$ walking. A data stream from a representative patient is shown in Fig. 3. From our inclinometer/accelerometer and calorimeter data, the cumulative EE above BMR during the activity period for sitting was $3 \pm 3 \mathrm{kcal}$, for

Table 1. Time allocation, Tracmor output, and energy expenditure for the activity period of the protocol

\begin{tabular}{lcc}
\hline \hline & Mean & SD \\
\hline Time allocation, \% & & \\
Lie & 22.6 & 5.46 \\
Sit & 23.5 & 3.75 \\
Stand & 21.2 & 4.11 \\
Walk & 33.2 & 5.68 \\
Tracmor output, U/min & & \\
Lie & 369 & 159 \\
Sit & 256 & 83 \\
Stand & 147 & 66 \\
Walk & 1,950 & 523 \\
Energy expenditure, kcal/min & & \\
Instruments & & \\
BMR & 1.03 & 0.12 \\
NEAT & 0.68 & 0.21 \\
NEAT/BMR & 0.39 & 0.07 \\
TEE & 1.71 & 0.26 \\
Room calorimeter & & \\
REE & 1.14 & 0.17 \\
NEAT & 0.80 & 0.23 \\
NEAT/BMR & 0.41 & 0.08 \\
TEE & 1.94 & 0.26 \\
\hline
\end{tabular}

Values are means \pm SD. BMR, basal metabolic rate; NEAT, nonexercise activity thermogenesis; TEE, total energy expenditure; REE, resting energy expenditure. 


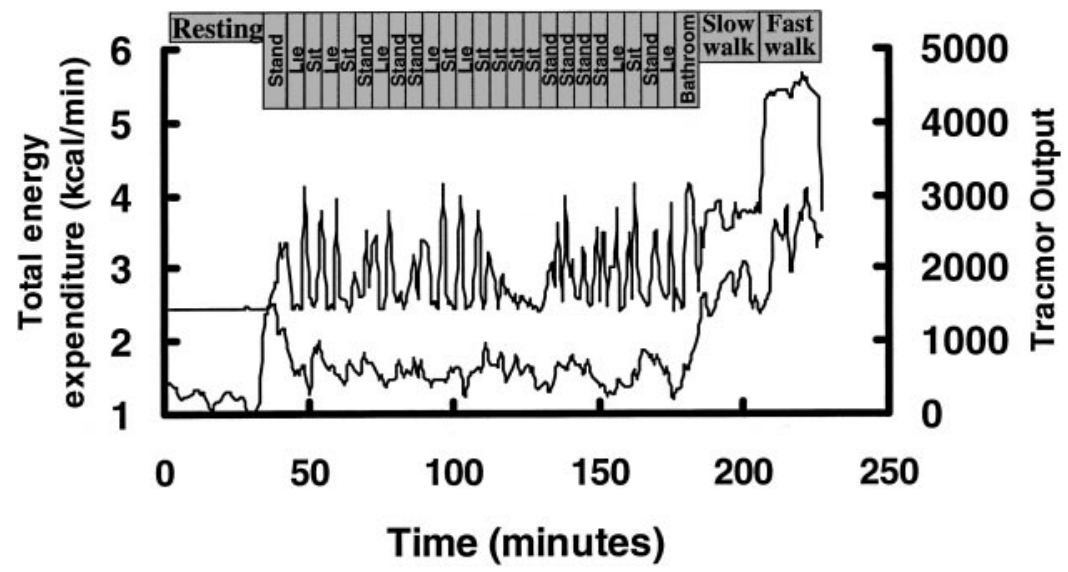

Fig. 3. Energy expenditure data and Tracmor output vs. time for 1 (male) subject. Lower line shows energy expenditure (EE) data and upper line Tracmor output. The upper blocks show the analyzed data from the inclinometers. standing was $8 \pm 4 \mathrm{kcal}$, for transitions was $2 \pm 1 \mathrm{kcal}$, and for walking was $108 \pm 28 \mathrm{kcal}$.

Overall, values for the activity period were: $\mathrm{NEAT}^{\text {Room calorimeter }}=145 \pm 38 \mathrm{kcal}$ (female, $135 \pm 30$; male, $155 \pm 47 \mathrm{kcal})$ and $\mathrm{NEAT}^{\text {Instruments }}=121 \pm 26$ kcal (female, $113 \pm 18$; male, $131 \pm 33 \mathrm{kcal}$ ).

On average, NEAT ${ }^{\text {Instruments }}$ was $85 \pm 9 \%$ of NEAT Room calorimeter. The intraclass correlation coefficient for the two methods was 0.86 , with $95 \%$ confidence intervals of 0.56 and 0.96 . This was significantly different from zero $(P<0.05)$. This suggests that $86 \%$ of the variance is attributable to between-subjects variance, and $100-86=14 \%$ to between-method disagreement.

Data for individual subjects are shown in Fig. 4. We used the regression equation for the relationship between NEAT ${ }^{\text {Instruments }}(x)$ and NEAT ${ }^{\text {Room calorimeter }}(y)$ $(y=1.3321 \times-16.969)$ to predict the error of NEAT estimated from the instruments. The mean error for NEAT predicted in this way was $10 \pm 11 \%$.

As we expected, NEAT ${ }^{\text {Instruments }}$ did not account for the total NEAT ${ }^{\text {Room calorimeter }}$. If it had, it would likely represent an overestimate, because $\mathrm{NEAT}^{\text {Instruments }}$ did not include the EE of fidgeting. As NEAT increased, the unaccounted-for component of NEAT increased. The unaccounted-for component of NEAT comprises fidgeting and/or error. We therefore wanted to know whether we could detect an increase in fidgeting with increasing NEAT.
To address this concern, we calculated for the activity period whether Tracmor output for nonwalking activities correlated with the difference in total EE between that measured in the room calorimeter and that calculated from our noninvasive instruments (Fig. 5); it did so. The Tracmor output for nonwalking activities (fidgeting) explained approximately one-half of the variance of unaccounted-for total EE.

\section{DISCUSSION}

NEAT represents a substantial component $(\sim 30$ $60 \%$ ) of total $\mathrm{EE}$ and the majority of nonresting $\mathrm{EE}$ (15). It is highly variable not only among people with different occupations (i.e., sedentary vs. nonsedentary occupations) but even among individuals who are sedentary (3). The importance of NEAT was underscored by our observation that its modulation predicted susceptibility to fat gain with overfeeding (13). This result was not surprising, because the components of NEAT, namely, sitting, standing, transitions, walking, and fidgeting, are associated with significant excursions of EE above resting $(8,9,14)$. Defining and measuring the components of NEAT are therefore important for understanding the mechanism by which NEAT might be regulated and, potentially, how NEAT might be important in obesity therapy (1). In this study, we used portable, stand-alone sensors to capture data on body position and motion and combined this information

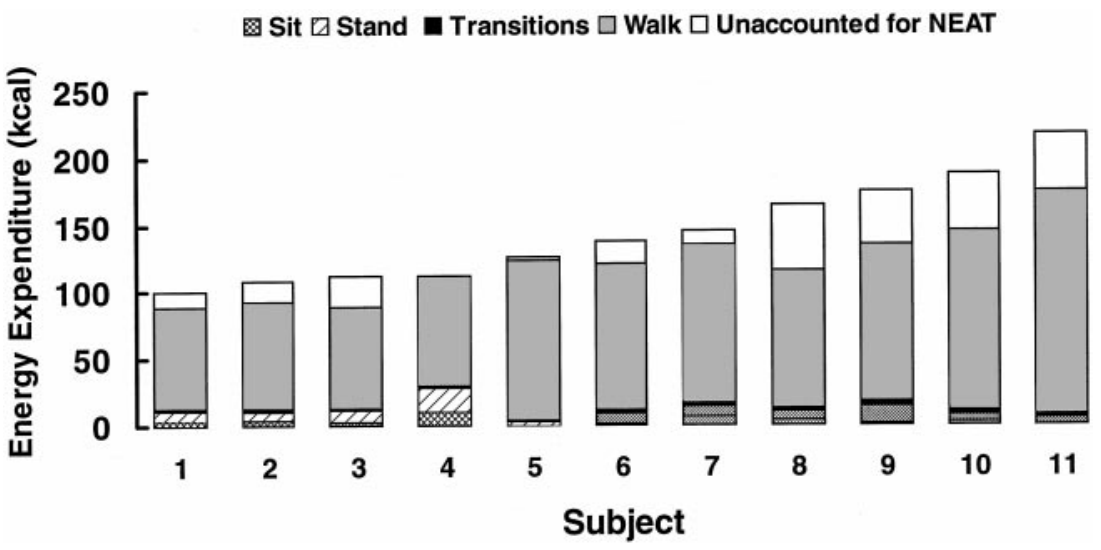

Fig. 4. Data for sitting, standing, transition, and walking $\mathrm{EE}$ as measured using the inclinometeraccelerometer-metabolic cart approach and measurements of total EE (TEE) performed using the room calorimeter for 11 healthy volunteers (females are subjects $1,2,5,6,8,9)$. Unaccounted-for nonexercise activity thermogenesis (NEAT) represents TEE (measured in the room calorimeter) minus the sum of sitting, standing, transition and walking energy expenditure. 


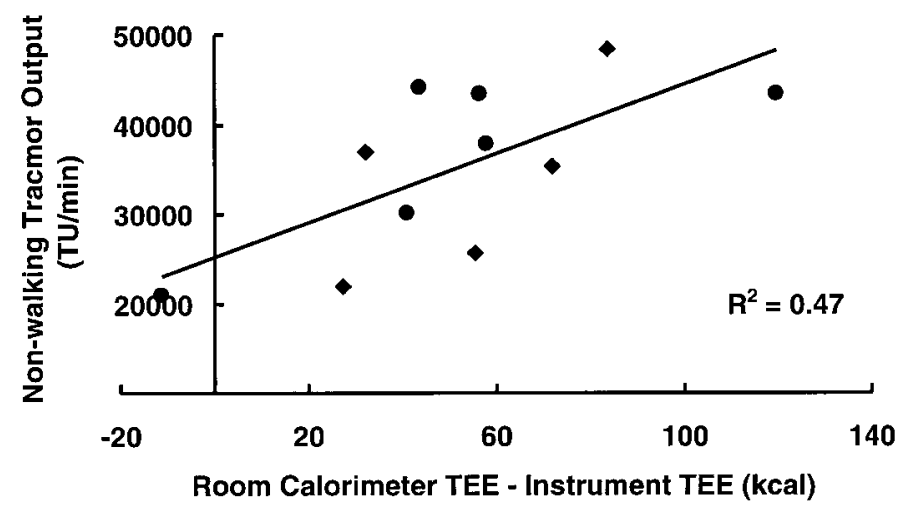

Fig. 5. Difference in TEE between room calorimeter measurement and TEE predicted from our instruments vs. nonwalking Tracmor output (females, $\bullet$, males, $\bullet$ ).

with laboratory measures of EE to predict NEAT. The value of this approach is well illustrated in Fig. 3, where the benefit of the additional information gained through the inclinometer data is self evident. The prediction of NEAT (albeit without a measurement of fidgeting) was compared with NEAT measured in a room calorimeter. The value for fidget-free NEAT determined from these instruments accounted for $86 \%$ of measured NEAT, and only $14 \%$ of the variance in the measures was attributable to method disagreement. Also, the accelerometer output for body motion while subjects were engaged in nonwalking activities explained one-half of the variance in the proportion of total EE that was not accounted for by our prediction of nonfidgeting NEAT. These results demonstrated that NEAT could be predicted using combined measurements of body position, motion, and laboratory determinations of EE.

Total NEAT can be estimated in nonexercising, freeliving individuals by use of doubly labeled water (7), which provides information on total daily EE over 7-10 days. When this measurement is combined with laboratory indirect calorimeter measurements of BMR and thermic effect of food (TEF), NEAT is calculated from: $\mathrm{NEAT}=$ total daily EE $-(\mathrm{BMR}+\mathrm{TEF})$. The principal limitation of this approach is that NEAT is calculated rather than measured, and this calculation does not enable an assessment of the components of NEAT. There have been repeated calls from statutory bodies such as the World Health Organization and the UN Food and Agriculture Organization to provide methods for directly assessing physical activity in free-living individuals (10). Although accelerometers and pedometers have been widely applied to detect body motion (2), these data are limited not only by variable precision but also because body motion can represent many different types of activity. The state-of-the-art method for detecting physical activity in free-living individuals is to have an investigator follow a subject continuously and record physical activity directly. Another limitation of doubly labeled water is that ${ }^{18} \mathrm{O}$ is expensive and in short supply, so that the number of measurements that can be performed is limited. Also, mass spectroscopy is necessary to measure ${ }^{2} \mathrm{H}$ and ${ }^{18} \mathrm{O}$ enrichments, to which many investigators do not have access. Hence, instruments that allow total NEAT and its components to be measured are potentially of great value for those interested in free-living physical activity and energy balance.

Despite its strengths and internal consistencies, there were several limitations to our study. First, the study was conducted in a room calorimeter. Such chambers limit free-living activity, walking in particular. However, we specifically modified the calorimeter to allow subjects to walk, and the data indicated that they readily did so. Second, the laboratory-based validation of these instruments occurred over a relatively short period of time. However, the objective of this study was to demonstrate the feasibility and to validate this approach in a laboratory environment where independent verification of activities could be obtained and NEAT be measured. If the results had failed to demonstrate a relationship between NEAT ${ }^{\text {Instruments }}$ and NEAT Room calorimeter, we could have deemed the approach, as we tested it, invalid. If we had applied these technologies to free-living subjects directly without rigorous validation, we would remain uncertain that the gathered data were valid. We viewed this study as critical before applying this technology to free-living individuals. Third, we did not obtain true BMR measurements in the room calorimeter; rather we used a measurement of resting $\mathrm{EE}$ as the room calorimeter baseline. When conducting an experiment such as this, we were eager to perform the metabolic cart measurements on the same day as the room calorimeter measurements. We did displace the treadmill component of the metabolic cart measurements until subjects left the room calorimeter, precisely so that the resting EE measurement in the room calorimeter would not be "postexercise." This approach was vindicated by the observation that the resting EE measurement on the room calorimeter was $10 \%$ above the BMR measurements, which is compatible with results from other investigators (16). Finally, the study was conducted on a seemingly small sample size, because the studies were complex to perform and required the dedicated use of a room calorimeter. Nonetheless, it was sufficient in size that we could account for $86 \%$ of the measurement variance.

We were not surprised that walking contributed to the majority of NEAT. Walking has been repeatedly demonstrated to be potently exothermic. Walking, even at $1 \mathrm{mph}$, doubles $\mathrm{EE}$ and at $3 \mathrm{mph}$ increases $\mathrm{EE}$ above resting by $250 \mathrm{kcal} / \mathrm{h}(14,18)$. Our observation would be consistent with the observation that Tracmor output correlated with total daily EE-to-BMR ratio in free-living human subjects (6). The true impact of walking on NEAT may have been overrepresented in this study, because walking may contribute less time proportionately in free-living subjects. Our future studies will address this issue.

In conclusion, by use of laboratory measures of $\mathrm{EE}$, inclinometers to determine body posture, and accelerometers to determine body locomotion, we are able to 
predict $\sim 86 \%$ of NEAT compared with a room calorimeter. In addition, accelerometer data during nonambulating allowed us to predict one-half of the variance in fidgeting. This provides us and others with a solid methodological foundation to measure NEAT in freeliving subjects.

Dr. A. Oberg, from the Department of Biostatistics, Mayo Foundation, is acknowledged for statistical support.

This work was supported in part by the Mayo Foundation and by National Institutes of Health Grants M01-RR-00051, DK-56650, and DK-48520.

\section{REFERENCES}

1. Andersen RE, Wadden TA, Bartlett SJ, Zemel B, Verde TJ, and Franckowiak SC. Effects of lifestyle activity vs. structured aerobic exercise in obese women: a randomized trial. JAMA 281: 335-340, 1999

2. Bassett DR, Ainsworth BE, Swartz AM, Strath SJ, O'Brien WL, and King GA. Validity of four motion sensors in measuring moderate intensity physical activity. Med Sci Sports Exerc 32: S471-S480, 2000.

3. Black AE, Coward WA, Cole TJ, and Prentice AM. Human energy expenditure in affluent societies: an analysis of 574 doubly-labelled water measurements. Eur J Clin Nutr 50: 72-92, 1996.

4. Bouten CV, Koekkoek KT, Verduin M, Kodde R, and Janssen JD. A triaxial accelerometer and portable data processing unit for the assessment of daily physical activity. IEEE Trans Biomed Eng 44: 136-147, 1997.

5. Bouten CV, Sauren AA, Verduin M, and Janssen JD. Effects of placement and orientation of body-fixed accelerometers on the assessment of energy expenditure during walking. Med Biol Eng Comput 35: 50-56, 1997.

6. Bouten CV, Verboeket-van de Venne WP, Westerterp KR, Verduin M, and Janssen JD. Daily physical activity assess- ment: comparison between movement registration and doubly labeled water. J Appl Physiol 81: 1019-1026, 1996.

7. Coward WA. Stable isotopic methods for measuring energy expenditure. The doubly-labelled-water $(2 \mathrm{H} 2,18 \mathrm{O})$ method: principles and practice. Proc Nutr Soc 47: 209-218, 1988.

8. Dauncey MJ. Activity and energy expenditure. Can J Physiol Pharmacol 68: 17-27, 1990.

9. Dietz WH, Bandini LG, Morelli JA, Peers KF, and Ching PL. Effect of sedentary activities on resting metabolic rate. Am $J$ Clin Nutr 59: 556-559, 1994.

10. FAO/WHO Expert Committee on Energy Requirements. Energy and Protein Requirements. Rome: FAO and WHO, 1973.

11. Jéquier E, Acheson K, and Schutz Y. Assessment of energy expenditure and fuel utilization in man. Annu Rev Nutr 7: 187-208, 1987.

12. Levine JA, Baukol PA, and Pavlidis Y. The energy expended chewing gum. $N$ Engl J Med 341: 2100, 1999.

13. Levine JA, Eberhardt NL, and Jensen MD. Role of nonexercise activity thermogenesis in resistance to fat gain in humans. Science 283: 212-214, 1999.

14. Levine JA, Schleusner SJ, and Jensen MD. Energy expenditure of nonexercise activity. Am J Clin Nutr 72: 1451-1454, 2000.

15. Ravussin E, Lillioja S, Anderson TE, Christin L, and Bogardus C. Determinants of 24-hour energy expenditure in man. Methods and results using a respiratory chamber. J Clin Invest 78: 1568-1578, 1986.

16. Shetty PS, Henry CJ, Black AE, and Prentice AM. Energy requirements of adults: an update on basal metabolic rates (BMRs) and physical activity levels (PALs). Eur J Clin Nutr 50, Suppl 1: S11-S23, 1996.

17. Sun M, Reed GW, and Hill JO. Modification of a whole room indirect calorimeter for measurement of rapid changes in energy expenditure. J Appl Physiol 76: 2686-2691, 1994.

18. Westerterp KR, Verboeket-van de Venne WP, Bouten CV, de Graaf C, van het Hof KH, and Weststrate JA. Energy expenditure and physical activity in subjects consuming full- or reduced-fat products as part of their normal diet. Br J Nutr 76: $785-795,1996$ 